\title{
Do Progestin-Only Contraceptives Contribute to the Risk of Developing Depression as Implied by Beta-Arrestin 1 Levels in Leukocytes? A Pilot Study
}

\author{
Keisha Smith, Sanket Nayyar, Tanu Rana, Anthony E. Archibong, Kimberly R. Looney and \\ Tultul Nayyar* \\ Department of Neuroscience \& Pharmacology, Meharry Medical College, 1005 Dr. D. B. Todd Jr. Blvd, Nashville, \\ TN 37208, USA; ksmith12@email.mmc.edu (K.S.); snayyar17@email.mmc.edu (S.N.); trana@mmc.edu (T.R.); \\ aarchibong@mmc.edu (A.E.A.); klooney@mmc.edu (K.R.L.) \\ * Correspondence: tnayyar@mmc.edu; Tel.: +1-615-327-6898
}

Received: 29 June 2018; Accepted: 7 September 2018; Published: 9 September 2018

check for updates

\begin{abstract}
We reported previously that reduction in beta-arrestin 1 ( $\beta$-AR 1$)$ protein levels in peripheral blood mononuclear leukocytes (PBMC) significantly correlated with the severity of depressive symptoms in reproductive women. In this pilot study, we used $\beta$-AR 1 protein levels in PBMC as a marker for developing depressive symptoms and the Hamilton Depression Rating Scale (HAM-D) scores to assess potential mood-related side effects of oral contraceptive use for routine birth control among women. We evaluated 29 women in this study. We enrolled the participants in three groups: Estrogen-progestin combination-oral contraceptives (COC, $n=10)$, progestin-only contraceptives (POC, $n=12)$, and non-hormonal or no contraceptives ( $\mathrm{NC}, n=7)$. We determined the $\beta$-AR 1 protein levels in PBMCs by enzyme-linked immunosorbent assay (ELISA). We found that women in the POC group had significantly higher HAM-D scores compared to those in the COC $(p<0.0004)$ and NC $(p<0.004)$. The levels of $\beta$-AR 1 protein were significantly attenuated in women in the POC group compared to women in the NC group $(p=0.03)$. Our findings suggest that the use of POC is a potential risk factor for developing depressive symptoms.
\end{abstract}

Keywords: beta-arrestin 1; depression; combination-oral contraceptives; progestin-only contraceptives; mononuclear leukocytes; women

\section{Introduction}

Depression and anxiety, among the most prevalent and disabling chronic diseases affecting reproductive-aged women worldwide, can contribute to adverse reproductive health outcomes. Women across different populations are twice as likely to experience depression as men during their reproductive years [1]. Depression and anxiety disorders also often go undetected and untreated among poor, unemployed, and less educated women [2]. Additionally, since contraceptive agents are widely used by reproductive women, it is important to know if any association exists between contraceptive use and depressive symptoms. It has been suggested in a review article that modern contraceptives with a lower-dosage of steroids do not have a clinically relevant impact on women's mood, as compared to higher doses of steroids that were used during the 1970's when depression was the known side effects of oral contraceptives use [3]. However, a long-term study on more than a million women in Denmark, with no history of depression for 13 years, found that those who used hormonal contraceptives had a fifty percent greater risk of developing depression within six months of using the contraceptives than those who did not use it [4].

Additional studies have delivered an ambiguous pattern of results. One study [5] found no association between oral contraceptive use and depressive symptoms, and others suggested $[6,7]$ that 
hormonal contraception was associated with better mood. Few other studies reported the development of depressive symptoms are a known reason for cessation of hormonal contraceptive use [8-10]. It was also found that non-hormonal or no contraceptive (NC) use (i.e., condoms and withdrawal vs. COCs and long-acting reversible contraception) to be associated with higher depressive and stress symptoms [11]. From this, it is evident that more studies are needed, in particular, to determine whether relationships differ according to the type of contraceptive agent used.

Currently, there are many different types of oral contraceptives available. Combination oral contraceptives containing both estrogen and progestin (COC) and progestin-only contraceptives (POC) are the two major types with so many variations in the composition of the components. Studies on COC and POC have yielded different results. A double-blind randomized placebo-controlled trial did not find an effect of COC on depressed mood [12], but progestins such as medroxyprogesterone acetate (MPA) in Depo-Provera [13] and levonorgestrel (LNG) in Mirena [4] have been reported to be associated with an increase in depressive symptom manifestation. Additional data suggests a protective effect of COC and a deleterious effect of POC with regards to mood disorders [14]. Moreover, a case study on a patient exhibited signs of self-mutilation and depressive symptoms three and a half weeks after using Depo-Provera; this patient did not have any significant personal or family psychiatric history [15]. Interestingly, a recent analysis of a retrospective study concluded that women using POC did not appear to experience more depressive symptoms or mood changes than women on other hormonal contraceptives, and that they may experience milder bouts of depression than women who did not use contraception [16]. Due to these contradicting findings, additional studies are warranted to determine the relationship between hormonal contraceptives and depressive symptoms, and whether such a relationship is dependent on the type of contraceptive used.

We present beta-arrestin 1 ( $\beta$-AR 1) protein level, a novel analyte in peripheral blood mononuclear leukocytes (PBMCs), which can be used as an early marker or may have mediated the observed changes in mood. The approach offers the scientific basis for a possible contraceptive side effect that has not been well-explained previously. The $\beta$-AR proteins, which regulate the $G$ protein receptor coupling, play an important role in the pathophysiology of mood disorders and in the mechanisms underlying the effects of antidepressants [17-20]. The $\beta$-AR 1 protein and mRNA levels in PBMCs of patients with untreated major depression were significantly lower than the levels found in healthy subjects and their levels also correlated significantly with the severity of the depressive symptoms $[17,18]$. Treatment with antidepressants elevated the $\beta$-AR 1 protein and mRNA levels [17,19]. We [21], along with others [17,22], proposed the $\beta$-AR 1 levels in PBMCs as a biochemical marker for depressive symptoms in humans. We reported that $\beta$-AR 1 protein levels were significantly lower in women with premenstrual dysphoric disorder (PMDD), a severe form of premenstrual syndrome (PMS), compared to those women with the non-severe form of PMS. Additionally, the reduction in $\beta$-AR 1 levels correlated with the increase in core symptoms of depression on the Hamilton Depression Rating Scale (HAM-D) [21]. Findings from these reports suggest that the assessment of $\beta$-AR-1 protein levels may prove useful for diagnosing depressive symptoms with high sensitivity and specificity [23].

Therefore, to assess potential mood-related side effects of oral contraceptives, we measured the $\beta$-AR-1 protein levels in PBMCs and recorded the HAM-D scores for women in the NC, COC, and POC groups on a single day when they were between days $21-25$ of the menstrual cycle, the susceptible period for PMS/PMDD. This period was selected because it has previously been suggested that women with PMS are more likely to suffer from depressive symptoms during COC use [24], and another study reported that certain combinations of progestogens are less suitable for women with PMS [25].

\section{Materials and Methods}

\subsection{Participant Recruitment}

Participant and Clinical Interaction Resource (PCIR) at the Meharry Clinical Research Center helped us recruit the participants for this study by putting up flyers, posting advertisements in 
publications approved by Meharry, and through recommendations from existing participants in similar studies. Inclusion criteria were as follows: (1) Women between 18-42 years of age who used either hormonal (estrogen-progestin combination agents, progestin-only agents) or non-hormonal contraceptives, and those in the same age group who did not use contraceptives for at least three months before enrollment in the study; (2) in good general health with no clinically significant systemic abnormalities; (3) did not suffer from chronic inflammatory diseases; (4) had not been treated with antidepressants within the last four weeks before the study; and (5) able to understand, read, and speak English, as well as understand the procedures and use/disclosure of protected health information (PHI) and subsequently give consent. Exclusion criteria were as follows: (1) history or evidence of clinically significant physical disorders; (2) existence or history of clinically significant and diagnosable major psychiatric disorders and/or chronic inflammatory diseases, as well as past diagnoses of schizophrenia, bipolar disorder, or primary anxiety disorder; and (3) any antidepressant/psychotropic drug or substance use within the past four weeks other than caffeine, and nicotine. Women using hormonal contraceptives for treatment or prophylaxis of gynecological (for e.g., heavy menstrual bleeding) or dermatological (for e.g., acne) conditions were also excluded.

Women interested in the study were given a complete description of the study. Written informed consent was obtained from the participants for a $24 \mathrm{~mL}$ blood donation. The women were evaluated using the Mini-International Neuropsychiatric Interview [26]. The severity of depression was determined using the 17-item HAM-D questionnaire. Participants with scores of $>19$ were considered depressed. The participants completed the HAM-D questionnaire before donating blood. The HAM-D scores and blood samples were collected when the women were between days 21-25 into their menstrual cycle. The participants were enrolled in the following groups: Estrogen-progestin combination-oral contraceptives (COC), progestin-only contraceptives (POC), and non-hormonal or no-contraceptives (NC). The NC group consisted of women with a regular menstrual cycle (25-33 days), who reported no use of hormonal contraceptives for at least three months prior in order to participate in this study. The study was approved by the Institutional Review Board at Meharry Medical College under the protocol number 15-03-364 (02/2018).

\subsection{HAM-D Scores}

The HAM-D score of each woman was calculated based on her answers to the HAM-D questionnaire as previously described [21] (where $0=$ absent). Briefly, depressed mood (0-4), difficulty in work activities (0-4), agitation (0-2), insomnia early (difficulty in falling asleep) (0-2), insomnia middle (complains of being restless and disturbed during the night) (0-2), insomnia late (waking in early hours of the morning and unable to fall asleep again) (0-2), psychological anxiety (0-4), somatic anxiety (gastrointestinal, indigestion, cardiovascular, palpitation, headaches, respiratory, and genitourinary, etc.) (0-4), and somatic symptoms (loss of appetite, heavy feeling in abdomen, and constipation) (0-2) [27].

\subsection{Isolation of Mononuclear Leukocytes}

Participant identities and group assignments for all blood samples were blinded upon collection using anonymized coding. Biochemical analyses were conducted by laboratory personnel who had no involvement or knowledge of the details of the sample collection. Vacutainer cell preparation tubes with sodium citrate (CPT) (BD Biosciences, San Jose, CA, USA) were used to collect $24 \mathrm{~mL}$ of blood from each participant using the venipuncture technique. Isolation of mononuclear leukocytes was performed according to the manufacturer's instructions. Briefly, CPT tubes were inverted gently to mix the blood with the anticoagulant additive and centrifuged at $1500 \times g$ at room temperature $\left(18-25^{\circ} \mathrm{C}\right.$ ) for a minimum of $20 \mathrm{~min}$. The mononuclear cells (the white buffy coat underneath the plasma layer) were collected into a $15-\mathrm{mL}$ conical tube, washed with phosphate buffered saline (PBS), and centrifuged at $400 \times g$ for $15 \mathrm{~min}$. The supernatant was discarded. The samples were washed again with PBS and centrifuged at $400 \times g$ for $10 \mathrm{~min}$. The cell pellets were stored at $-80^{\circ} \mathrm{C}$ for later use. 


\subsection{Enzyme-Linked Immunosorbent Assay (ELISA)}

The protein was extracted from the PBMC samples by using $200 \mu \mathrm{L}$ of Pierce RIPA Buffer (Pierce BioTechnology; Rockville, IL, USA product \#89900) containing Halt protease inhibitor cocktail (Pierce BioTechnology; Rockville, IL, USA product \#783430). The mixture was centrifuged at a maximum speed for $15 \mathrm{~min}$. The supernatant was collected and stored at $-80^{\circ} \mathrm{C}$ for ELISA. The ELISA protocol from the manufacturer (Human Arrestin $\beta 1$ :ARR $\beta 1$ ELISA kit; MyBioSource, San Diego, CA, USA, catalog \# MBS725731) was used to determine the levels of $\beta$-AR 1 protein. All assays were done in duplicates and measurements were obtained using the xMark microplate spectrophotometer (Bio-Rad Laboratories, Inc., Hercules, CA, USA). Briefly, $10 \mu \mathrm{L}$ of balance solution and $50 \mu \mathrm{L}$ of the conjugate were added to each well, except the blank control well. The plate was mixed using a plate shaker and incubated for $1 \mathrm{~h}$ at $37^{\circ} \mathrm{C}$. Next, the mixture was removed and the plate was washed five times with $1 \times$ wash solution. Then, $50 \mu \mathrm{L}$ of substrate $\mathrm{A}$ and $50 \mu \mathrm{L}$ substrate $\mathrm{B}$ were added to each well. The plate was covered and incubated for $15 \mathrm{~min}$ at $37^{\circ} \mathrm{C}$. Finally, $50 \mu \mathrm{L}$ of stop solution was added to each well and the plate was read at $450 \mathrm{~nm}$. The $\beta$-AR 1 protein level in each sample was determined using a standard curve constructed for each assay. The protein concentrations of each sample was determined using the BCA assay (Pierce BioTechnology; Rockville, IL, USA, product \#23225). The $\beta$-AR 1 protein level in each sample was then calculated based on the total protein content of each sample to obtain the $\beta$-AR 1 level as ng per mg of protein. The standard curve and the $\% \mathrm{CV}$ for the duplicate samples were all within the acceptable range for each assay.

\subsection{Statistical Analyses}

Results are expressed as mean \pm SEM unless otherwise indicated. The GraphPad Prism software (Graph-Pad Software, Inc., San Diego, CA, USA) was used for all the statistical analysis. Results with $p<0.05$ were considered statistically significant. Data were analyzed by ANOVA using the contraceptive type as a factor in three levels, followed by post-hoc analyses using Bonferroni's multiple comparisons when a significant effect was revealed by ANOVA. Regression analyses were conducted between the type of contraceptive and the $\beta$-AR 1 protein levels. Potential confounders (race, age, body weight, smoking behavior, and the day of the menstrual cycle when blood samples and HAM-D scores were collected) were also assessed.

\section{Results}

\subsection{Demographics}

A total of 29 women $(\mathrm{NC}=7, \mathrm{COC}=10, \mathrm{POC}=12)$ participated in this study. Participant characteristics are listed in Table 1.

The body weights of women in the POC group were significantly lower than those of women in the NC group $(p<0.05)$. There was no significant difference in body weights between women in the NC group and those in the COC group $(p=0.19)$, and between women in the COC group and those in the POC group $(p=0.75)$. 
Table 1. Participant characteristics.

\begin{tabular}{|c|c|c|c|}
\hline Women $(n)=29$ & $\mathrm{NC}(n=7,24 \%)$ & $\operatorname{COC}(n=10,34 \%)$ & POC $(n=12,41 \%)$ \\
\hline Black & 5 & 8 & 12 \\
\hline White & 2 & 2 & - \\
\hline Age (Average, Range) & $31(32-38)$ & $28(24-36)$ & $29(19-38)$ \\
\hline Weight (Average, Range) & $237(170-360)$ & $188(126-240)$ & $173(116-254)$ \\
\hline \multirow{2}{*}{\multicolumn{4}{|c|}{$\begin{array}{l}\text { NC vs. POC, } p=0.05^{*} \\
\text { NC vs. COC, } p=0.19\end{array}$}} \\
\hline \multirow{2}{*}{\multicolumn{4}{|c|}{$\begin{array}{c}\text { NC vs. COC, } p=0.19 \\
\text { COC vs. POC, } p=0.75\end{array}$}} \\
\hline & & & \\
\hline Smoker & 3 & - & 2 \\
\hline Nonsmoker & 4 & 10 & 10 \\
\hline Pregnancies (Average, Range) & $2(0-5)$ & $0(0-1)$ & $2(0-5)$ \\
\hline Children \# (Average, Range) & $2(0-4)$ & 0 & $2(0-4)$ \\
\hline \multirow{5}{*}{$\begin{array}{l}\text { Contraceptives } \\
\text { (Name, Number) }\end{array}$} & Essure $^{\circledR} 1$ & Orthro Tri-Cyclen ${ }^{\circledR} 3$ & Mini-Pill (Norethindrone) 2 \\
\hline & Paragard $^{\circledR} 1$ & Necon $1 / 35^{\circledR} 2$ & IUD (Mirena $\left.{ }^{\circledR}\right) 4$ \\
\hline & No contraceptive 5 & Junel Fe $1 / 20^{\circledR} 2$ & IUD (Kyleena $\left.{ }^{\circledR}\right) 1$ \\
\hline & & Generic Yaz 1 & Implant (Nexplanon $\left.{ }^{\circledR}\right) 4$ \\
\hline & & Lo Loestrin $\mathrm{Fe}^{\circledR} 2$ & Injection (Depo Provera ${ }^{\circledR}$ ) 1 \\
\hline
\end{tabular}

NC, non-hormonal or no contraceptives; COC, estrogen-progestin combination-oral contraceptives; POC, progestin-only contraceptives; IUDs, Intrauterine devices; * Significantly different.

\subsection{HAM-D Scores}

Based on the participants' HAM-D scores, we found that out of 29 women, $23(79 \%)$ women were not depressed (HAM-D $<19 ; 8.0 \pm 1.09)$ and six $(21 \%)$ were depressed (HAM-D > 19; $20.22 \pm 1.3)$. The body weight of not depressed (202 \pm 13.37$)$ vs. depressed (160.4 \pm 14.28$)$ women were not statistically significant $(p=0.19)$. All the six depressed women belonged to the POC group. The group-wise analysis of HAM-D scores are as follows: NC, (7.42 \pm 1.63 , CI 95\% 3.43-11.42); COC, $(6.1 \pm 1.86$, CI 95\% 1.88-10.32); and POC, (17.08 \pm 1.82 , CI 95\% 13.07-21.1). ANOVA revealed that the types of contraceptives used significantly affected the HAM-D scores $(F[2,26]=11.64, p=0.0002)$. Post-hoc analyses revealed that women in the POC group had significantly higher HAM-D scores than those in the COC group $(p<0.0004)$ and the NC group $(p<0.004)$ (Figure 1$)$.

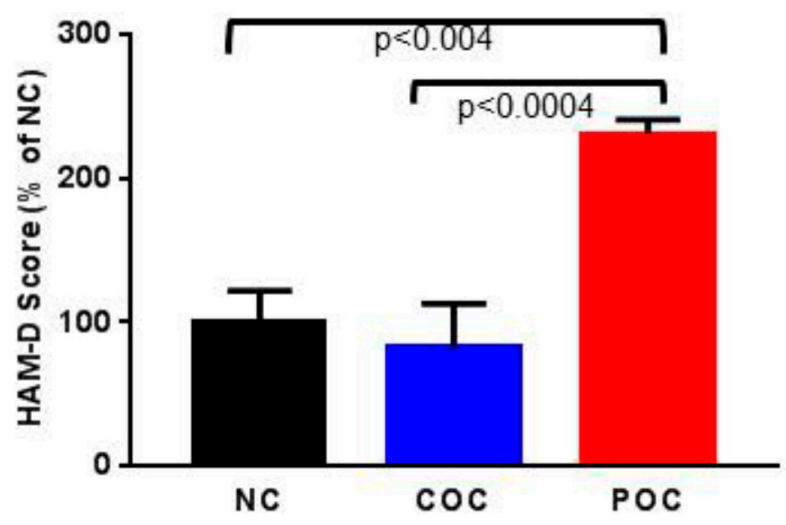

Figure 1. The HAM-D scores (mean \pm SEM) among women using non-hormonal or no contraceptives (NC), estrogen-progestin combination-oral contraceptives (COC), and progestin-only contraceptives (POC) were compared. Data are expressed as percentages of values for women in the NC group. Women in the POC group scored significantly higher on HAM-D than women in the NC group $(p<0.004)$ or women in the COC group $(p<0.0004)$. There was no significant difference in the HAM-D score between NC and COC women $(p=0.42)$.

ANOVA assessing the core symptoms of depression on the HAM-D scale demonstrated significant differences in the following parameters: Insomnia early, $(\mathrm{F}[2,21]=3.88, p=0.03)$; insomnia middle, $(\mathrm{F}[2,21]=6.55, p=0.006) ;$ psychological anxiety, $(\mathrm{F}[2,21]=6.12, p=0.008)$; somatic anxiety, $(\mathrm{F}[2,21]=4.16, p=0.03)$; and somatic symptoms, $(\mathrm{F}[2,21]=5.16, p=0.01)$. Post-hoc analysis 
revealed that women in the POC group had significantly higher scores for the following characteristics: Insomnia early $(p=0.04)$, insomnia middle $(p=0.01)$, psychological anxiety $(p=0.02)$, and somatic symptoms $(p=0.02)$ compared to women in the NC group. Women in the POC group also had significantly higher scores for insomnia middle $(p=0.02)$ and psychological anxiety $(p=0.01)$, than women in the COC group. However, post-hoc tests did not reveal any significant difference in somatic anxiety among the three groups. There was also no significant difference in the scores for any of the core symptoms of depression between women in the NC group and those in the COC group (Table 2).

Table 2. Core symptoms of depression on the HAM-D scale (mean \pm SEM).

\begin{tabular}{ccccccc}
\hline Core Symptoms & NC & COC & POC & $\begin{array}{c}\text { NC/COC } \\
(p \text { Value })\end{array}$ & $\begin{array}{c}\text { NC/POC } \\
p \text { Value })\end{array}$ & $\begin{array}{c}\text { COC/POC } \\
(p \text { Value })\end{array}$ \\
\hline Depressed mood & $1.0 \pm 0.25$ & $0.88 \pm 0.35$ & $2.0 \pm 0.37$ & $>0.99$ & 0.12 & 0.07 \\
Work \& activities & $0.83 \pm 0.4$ & $0.44 \pm 0.17$ & $1.44 \pm 0.37$ & $>0.99$ & 0.64 & 0.08 \\
Feelings of guilt & $0.33 \pm 0.21$ & $0.33 \pm 0.23$ & $1.2 \pm 0.32$ & $>0.99$ & 0.12 & 0.07 \\
Agitation & $0.5 \pm 0.34$ & $0.5 \pm 0.33$ & $1.0 \pm 0.23$ & $>0.99$ & 0.85 & 0.86 \\
Early insomnia & $0.16 \pm 0.16$ & $0.44 \pm 0.17$ & $1.11 \pm 0.3$ & $>0.99$ & $0.04^{*}$ & 0.15 \\
Middle insomnia & $0.16 \pm 0.16$ & $0.33 \pm 0.16$ & $1.2 \pm 0.27$ & $>0.99$ & $0.01^{*}$ & $0.02^{*}$ \\
Late insomnia & $0.16 \pm 0.16$ & $0.55 \pm 0.24$ & $0.77 \pm 0.22$ & 0.78 & 0.25 & $>0.99$ \\
Psychological anxiety & $0.33 \pm 0.21$ & $0.44 \pm 0.24$ & $1.6 \pm 0.37$ & $>0.99$ & $0.02^{*}$ & $0.01^{*}$ \\
Somatic anxiety & $0.66 \pm 0.33$ & $0.77 \pm 0.32$ & $2.0 \pm 0.4$ & $>0.99$ & 0.07 & 0.06 \\
Somatic symptoms & $>0.99$ & $0.22 \pm 0.14$ & $0.77 \pm 0.22$ & $>0.99$ & $0.02 *$ & 0.07 \\
\hline
\end{tabular}

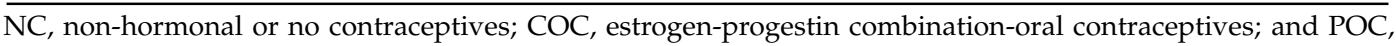
progestin-only contraceptives. * Statistically significant $(p<0.05)$.

\section{3. $\beta$-AR 1 Protein Levels}

The $\beta$-AR 1 protein levels in PBMCs were as follows: NC, $4.44 \pm 0.40$; COC, $3.57 \pm 0.76$; and POC, $2.87 \pm 0.39$. Though our data seems to imply a downward trend in $\beta$-AR 1 levels, i.e., NC $>$ COC > POC, ANOVA did not reveal any significant effect of contraceptive types on $\beta$-AR 1 levels. Nonetheless, regression analysis demonstrated that $\beta$-AR 1 protein levels in women in the POC group were significantly attenuated compared to those in women in the NC group $(p=0.03)$. There was no statistically significant difference in $\beta$-AR 1 protein levels between women in the NC group and those in the COC group $(p=0.81)$, and between women in the COC group and those in the POC group $(p=0.052)$ (Figure 2$)$.

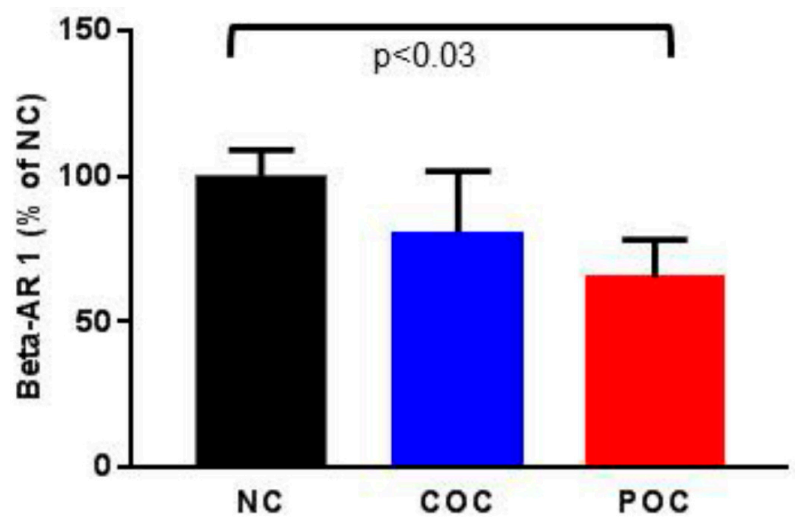

Figure 2. The $\beta$-arrestin 1 protein levels (mean \pm SEM) in the leukocytes were compared among women using non-hormonal or no contraceptives (NC), estrogen-progestin combination-oral contraceptives (COC), and progestin-only contraceptives (POC). Data are expressed as percentages of values for women in the NC group. The $\beta$-arrestin $1(\mathrm{ng} / \mathrm{mg})$ levels were significantly attenuated in women in the POC group, compared to women in the NC group $(p<0.03)$. There were no statistically significant differences in the $\beta$-AR 1 levels between women in the NC group and those in the COC group, and between women in the COC group and those in the POC group. 
Table 3 compares the $\beta$-AR 1 levels with the independently obtained HAM-D scores among women in the $\mathrm{NC}, \mathrm{COC}$, and POC groups. We found that women in the POC group had significantly higher HAM-D scores compared to those in the NC group and COC group. Interestingly, women in the POC group also had lower levels of $\beta$-AR 1 protein than women in the NC group.

Table 3. Comparison of $\beta$-AR 1 protein levels (ng/mg) with independently obtained HAM-D score among women in the $\mathrm{NC}, \mathrm{COC}$, and POC groups.

\begin{tabular}{cccc}
\hline Outcomes & NC & COC & POC \\
\hline$\beta$-AR 1 (Mean \pm SEM) & $4.44 \pm 0.40$ & $3.57 \pm 0.76$ & $2.87 \pm 0.39$ \\
NC vs. POC, $p=0.03^{*}$ & & & \\
NC vs. COC, $p=0.81$ & & & \\
COC vs. POC, $p=0.052$ & & & \\
\hline HAM-D (Mean \pm SEM) & $6.0 \pm 1.3$ & & \\
NC vs. POC, $p=0.004^{* *}$ & & & \\
NC vs. COC, $p=0.42$ & & & \\
COC vs. POC, $p=0.0004^{* * *}$ & & & \\
\hline
\end{tabular}

$\mathrm{NC}$, non-hormonal or no contraceptives; COC, estrogen-progestin combination-oral contraceptives; POC, progestin-only contraceptives; $\beta$-AR 1, $\beta$-arrestin 1; HAM-D, Hamilton Depression Rating Scale; and NS, not significant. ${ }^{*} p<0.05,{ }^{* *} p<0.005,{ }^{* * *} p<0.0005$.

\subsection{Potential Confounders}

We also assessed potential confounders (race, age, body weight, smoking behavior, number of pregnancy, number of children, and the day of the menstrual cycle when blood samples and HAM-D scores were collected) that could affect the HAM-D scores and $\beta$-AR 1 protein levels. We found that none of these factors yielded significant effects on either the HAM-D scores or $\beta$-AR 1 protein levels (data not shown).

\section{Discussion}

This study offers a scientific basis for determining possible mood-related side effects of oral contraceptives that have not been explored previously. From a group of 29 participating women, we found that women in the POC group had attenuated $\beta$-AR 1 protein levels compared to women in the $\mathrm{NC}$ group. We and others have demonstrated previously that reduction in the $\beta$-AR 1 protein levels significantly correlated with the development of depressive symptoms $[17,18,21]$.

Our HAM-D score data revealed that six out of the 12 women in the POC group were depressed (HAM-D > 19). In contrast, participants in the COC and NC groups were not depressed. Among the several core symptoms of depression on the HAM-D scale, scores for insomnia (early and middle), somatic symptoms, and psychological activity were significantly higher among women in the POC group compared to those in the NC group. Furthermore, scores for insomnia (middle) and psychological activity were also significantly higher among women in the POC group than women in the COC group (Table 2). These findings are in line with previous studies reporting an increase in depressive symptoms associated with the use of POC $[13,28,29]$. Our data on $\beta$-AR 1 protein levels revealed that women in the POC group exhibited a significant reduction in $\beta$-AR 1 levels compared to women in the NC group (Figure 2). We and others have previously shown the reduction in $\beta$-AR 1 levels to be significantly correlated with the HAM-D scores $[17,18,21]$. In this study, we found that women in the POC group had higher HAM-D scores and showed a reduction in $\beta$-AR 1 protein levels compared to women in the COC group, although the difference in $\beta$-AR 1 protein levels is not statistically significant (Table 3). We also found that women in the COC group had HAM-D scores and $\beta$-AR 1 levels that were similar to those for women in the NC group (Table 3). Therefore, we postulate that the use of POC may be a potential risk factor for developing depressive symptoms. Since $\beta$-AR 1 has been shown to facilitate estrogen-mediated neuroprotection [30], it is possible that the estrogen in COC attenuates a progestin's effect on $\beta$-AR 1 levels. 
There are some plausible mechanisms that may explain the relationship between the use of contraceptives and mood status. Ovarian hormones have been shown to play a role in serotonin neurotransmission [31-33], which is the most relevant pathophysiological correlate of depression [34]. Serotonin neurotransmission involves G-protein-coupled receptor (GPCR) signaling [35], in which $\beta$-AR 1 plays a pivotal role [18]. Progestins, which are a type of synthetic progesterone, not only mimic the actions of endogenous progesterone, but also have divergent biological effects with respect to endogenous progesterone. Preclinical studies have shown that progesterone and progestins can modulate brain functions through differential binding and the activation of progesterone receptors, activation of various intracellular pathways, and differential modulation of the synthesis and release of several neurotransmitters including serotonin [36,37]. Adverse mood effects induced by POC may also be due to the action of progesterone metabolites on the $\gamma$-aminobutyric acid receptor complex [38], which has a documented role in mood regulation [39]. External progestins increase levels of monoamine oxidase, possibly more effectively than endogenous progesterone does; hence, progestins can potentially degrade serotonin more rapidly and thus enhances the symptoms of depression and irritability [40]. Estrogens are shown to increase serotonin levels [41] and have an antidepressant-like effect on neurotransmitters such as those present in the dopaminergic, catecholaminergic, and GABAergic neurons [42]. Therefore, it is possible that the estrogen in the COC reduces the risk of developing depressive symptoms among women who use COC [43].

Several limitations exist for this study, including a small sample size, selection bias, and a demographic imbalance. This study did not analyze the following factors: The length of time hormonal contraceptives were used, data on miscarriages and abortions, assessment of life events, and psychosocial factors [44,45]. The categories of contraception listed (NC, COC, and POC products) are quite heterogeneous, with individual methods within those categories having different effects and mechanisms of action. With POCs in particular, DMPA (higher serum levels of progestin) vs. progestin-only pills or IUDs (lower serum levels of progestin) have different effects on brain chemistry, and several different progestins combined with the varying amount of estrogen component in COCs act differently on mood symptoms [46].

\section{Conclusions}

Safe and effective methods of contraception represent a critical component of preventive health care. The implications derived from our findings show an association between POC and depressive symptoms, in addition to $\beta$-AR 1 protein levels in PBMC, as a possible biomarker and mechanism mediating the observed association. In conclusion, this pilot study points to the use of POC as a potential risk factor for developing depressive symptoms. It can be assumed that not all depressive symptoms experienced by POC users are drug-related. In future studies, a larger number of subjects should preferably be followed prospectively for HAM-D scores and $\beta$-AR 1 protein levels before the start of COC or POC agent use. With such a study design, it would be possible to identify subjects who develop depressive symptoms due to COC or POC use, and will be able to confirm the causal relationship between developing depressive symptoms and the type of contraceptive agent use. While most women will not experience clinical depression soon after starting hormonal contraceptives, doctors should be on the lookout for potential changes in mood in the first few months. Additionally, women starting on any kind of hormonal contraceptive should be careful to note any changes-good or bad, physical or mental-and discuss them with a doctor.

Author Contributions: Conceptualization, K.S., S.N. and T.N.; Data curation, K.S.; Formal analysis, T.N.; Funding acquisition, T.N.; Methodology, K.S. and T.R.; Resources, K.L.; Software, S.N.; Supervision, T.N.; Writing-original draft, T.N.; Writing-review \& editing, A.A. and T.N.

Funding: This study was supported by U54 MD007593-07 (Nayyar) from NIMHD.

Acknowledgments: We thank all 29 women for their participation in this study. We would like to thank Krystal Smith and Marche' Jackson for their technical assistance. We also thank the PCIR, Morphology Core Laboratory, 
and the Institutional Review Board of Meharry Medical College. Finally, we would like to thank Meharry Office for Scientific Editing and Publications for scientific and language editing support.

Conflicts of Interest: The authors declare no conflict of interest.

\section{References}

1. Hammarstrom, A.; Lehti, A.; Danielsson, U.; Bengs, C.; Johansson, E.E. Gender-related explanatory models of depression: A critical evaluation of medical articles. Public Health 2009, 123, 689-693. [CrossRef] [PubMed]

2. Farr, S.L.; Dietz, P.M.; Williams, J.R.; Gibbs, F.A.; Tregear, S. Depression screening and treatment among non-pregnant women of reproductive age in the United States, 1990-2010. Prev. Chronic Dis. 2011, 8, 1-15.

3. Hall, K.S.; Steinberg, J.R.; Cwiak, C.A.; Allen, R.H.; Marcus, S.M. Contraception and mental health: A commentary on the evidence and principles for practice. Am. J. Obstet. Gynecol. 2015, 212, 740-746. [CrossRef] [PubMed]

4. Skovlund, C.W.; Morch, L.S.; Kessing, L.V.; Lidegaard, O. Association of hormonal contraception with depression. JAMA Psychiatry 2016, 73, 1154-1162. [CrossRef] [PubMed]

5. Duke, J.M.; Sibbritt, D.W.; Young, A.F. Is there an association between the use of oral contraception and depressive symptoms in young Australian women? Contraception 2007, 75, 27-31. [CrossRef] [PubMed]

6. Toffol, E.; Heikinheimo, O.; Koponen, P.; Luoto, R.; Partonen, T. Further evidence for lack of negative associations between hormonal contraception and mental health. Contraception 2012, 86, 470-480. [CrossRef] [PubMed]

7. Keyes, K.M.; Cheslack-Postava, K.; Westhoff, C.; Heim, C.M.; Haloossim, M.; Walsh, K.; Koenen, K. Association of hormonal contraceptive use with reduced levels of depressive symptoms: A national study of sexually active women in the United States. Am. J. Epidemiol. 2013, 178, 1378-1388. [CrossRef] [PubMed]

8. Rosenberg, M.J.; Waugh, M.S. Oral contraceptive discontinuation: A prospective evaluation of frequency and reasons. Am. J. Obstet. Gynecol. 1998, 179, 577-582. [CrossRef]

9. Sanders, S.A.; Graham, C.A.; Bass, J.L.; Bancroft, J. A prospective study of the effects of oral contraceptives on sexuality and well-being and their relationship to discontinuation. Contraception 2001, 64, 51-58. [CrossRef]

10. Poromaa, I.S.; Segebladh, B. Adverse mood symptoms with oral contraceptives. Acta Obstet. Gynecol. Scand. 2012, 91, 420-427. [CrossRef] [PubMed]

11. Hall, K.; Moreau, C.; Trussell, J.; Barber, J. Role of young women's depression and stress symptoms in their weekly use and nonuse of contraceptive methods. J. Adolesc. Health 2013, 53, 241-248. [CrossRef] [PubMed]

12. Zethraeus, N.; Dreber, A.; Ranehill, E.; Blomberg, L.; Labrie, F.; von Schoultz, B.; Johannesson, M.; Hirschberg, A.L. A first-choice combined oral contraceptive influences general well-being in healthy women: A double-blind, randomized, placebo-controlled trial. Fertil. Steril. 2017, 107, 1238-1245. [CrossRef] [PubMed]

13. Archer, B.; Irwin, D.; Jensen, K.; Johnson, M.E.; Rorie, J. Depot medroxyprogesterone. Management of side-effects commonly associated with its contraceptive use. J. Nurse Midwifery 1997, 42, 104-111. [CrossRef]

14. Svendal, G.; Berk, M.; Pasco, J.A.; Jacka, F.N.; Lund, A.; Williams, L.J. The use of hormonal contraceptive agents and mood disorders in women. J. Affect. Disord. 2012, 140, 92-96. [CrossRef] [PubMed]

15. St-Andre, M.; Stikarovska, I.; Gascon, S. Clinical case rounds in child and adolescent psychiatry: De novo self-mutilation and depressive symptoms in a 17-year-old adolescent girl receiving depot-medroxyprogesterone acetate. J. Can. Acad. Child Adolesc. Psychiatry 2012, 21, 59-62. [PubMed]

16. Kuntz, K.; McCullough, S.; Beach, P. Do progesterone-only contraceptives lead to more mood changes than other types? J. Fam. Pract. 2016, 65, 938-943. [PubMed]

17. Avissar, S.; Matuzany-Ruban, A.; Tzukert, K.; Schreiber, G. Beta-arrestin-1 levels: Reduced in leukocytes of patients with depression and elevated by antidepressants in rat brain. Am. J. Psychiatry 2004, 161, 2066-2072. [CrossRef] [PubMed]

18. Schreiber, G.; Golan, M.; Avissar, S. Beta-arrestin signaling complex as a target for antidepressants and as a depression marker. Drug News Perspect. 2009, 22, 467-480. [PubMed]

19. Golan, M.; Schreiber, G.; Avissar, S. Antidepressants increase beta-arrestin 2 ubiquitinylation and degradation by the proteasomal pathway in C6 rat glioma cells. J. Pharmacol. Exp. Ther. 2010, 332, 970-976. [CrossRef] [PubMed] 
20. David, D.J.; Samuels, B.A.; Rainer, Q.; Wang, J.W.; Marsteller, D.; Mendez, I.; Drew, M.; Craig, D.A.; Guiard, B.P.; Guilloux, J.P.; et al. Neurogenesis-dependent and -independent effects of fluoxetine in an animal model of anxiety/depression. Neuron 2009, 62, 479-493. [CrossRef] [PubMed]

21. Alam, F.; Nayyar, S.; Richie, W.; Archibong, A.; Nayyar, T. Beta-arrestin 1 levels in mononuclear leukocytes support depression scores for women with premenstrual dysphoric disorder. Int. J. Environ. Res. Public Health 2016, 13, 43. [CrossRef] [PubMed]

22. Mendez-David, I.; El-Ali, Z.; Hen, R.; Falissard, B.; Corruble, E.; Gardier, A.M.; Kerdine-Romer, S.; David, D.J. A method for biomarker measurements in peripheral blood mononuclear cells isolated from anxious and depressed mice: Beta-arrestin 1 protein levels in depression and treatment. Front. Pharmacol. 2013, 4, 124-128. [CrossRef] [PubMed]

23. Golan, M.; Schreiber, G.; Avissar, S. Antidepressant-induced differential ubiquitination of beta-arrestins 1 and 2 in mononuclear leucocytes of patients with depression. Int. J. Neuropsychopharmacol. 2013, 16, 1745-1754. [CrossRef] [PubMed]

24. Cullberg, J. Mood changes and menstrual symptoms with different gestagen/estrogen combinations. A double blind comparison with a placebo. Acta Psychiatr. Scand. Suppl. 1972, 236, 1-86. [PubMed]

25. Backstrom, T.; Hansson-Malmstrom, Y.; Lindhe, B.A.; Cavalli-Bjorkman, B.; Nordenstrom, S. Oral contraceptives in premenstrual syndrome: A randomized comparison of triphasic and monophasic preparations. Contraception 1992, 46, 253-268. [CrossRef]

26. Sheehan, D.V.; Lecrubier, Y.; Sheehan, K.H.; Amorim, P.; Janavs, J.; Weiller, E.; Hergueta, T.; Baker, R.; Dunbar, G.C. The Mini-International Neuropsychiatric Interview (M.I.N.I.): The development and validation of a structured diagnostic psychiatric interview for DSM-IV and ICD-10. J. Clin. Psychiatry 1998, 59, 22-33. [PubMed]

27. Hamilton, M. A rating scale for depression. J. Neurol. Neurosurg. Psychiatry 1960, 23, 56-62. [CrossRef] [PubMed]

28. Sangi-Haghpeykar, H.; Poindexter, I.I.I.A.N.; Bateman, L.; Ditmore, J.R. Experiences of injectable contraceptive users in an urban setting. Obstet. Gynecol. 1996, 88, 227-233. [CrossRef]

29. Fraser, I.S.; Dennerstein, G.J. Depo-Provera use in an Australian metropolitan practice. Med. J. Aust. 1994, 160, 553-556. [PubMed]

30. Dominguez, R.; Hu, E.; Zhou, M.; Baudry, M. 17beta-estradiol-mediated neuroprotection and ERK activation require a pertussis toxin-sensitive mechanism involving GRK2 and beta-arrestin-1. J. Neurosci. 2009, 29, 4228-4238. [CrossRef] [PubMed]

31. Bethea, C.L.; Lu, N.Z.; Gundlah, C.; Streicher, J.M. Diverse actions of ovarian steroids in the serotonin neural system. Front. Neuroendocrinol. 2002, 23, 41-100. [CrossRef] [PubMed]

32. Lu, N.Z.; Eshleman, A.J.; Janowsky, A.; Bethea, C.L. Ovarian steroid regulation of serotonin reuptake transporter (SERT) binding, distribution, and function in female macaques. Mol. Psychiatry 2003, 8, 353-360. [CrossRef] [PubMed]

33. Smith, L.J.; Henderson, J.A.; Abell, C.W.; Bethea, C.L. Effects of ovarian steroids and raloxifene on proteins that synthesize, transport, and degrade serotonin in the raphe region of macaques. Neuropsychopharmacology 2004, 29, 2035-2045. [CrossRef] [PubMed]

34. Muller, N.; Schwarz, M.J. The immune-mediated alteration of serotonin and glutamate: Towards an integrated view of depression. Mol. Psychiatry 2007, 12, 988-1000. [CrossRef] [PubMed]

35. Millan, M.J.; Marin, P.; Bockaert, J.; la Cour, C.M. Signaling at G-protein-coupled serotonin receptors: Recent advances and future research directions. Trends Pharmacol. Sci. 2008, 29, 454-464. [CrossRef] [PubMed]

36. Nilsen, J.; Brinton, R.D. Divergent impact of progesterone and medroxyprogesterone acetate (Provera) on nuclear mitogen-activated protein kinase signaling. Proc. Natl. Acad. Sci. USA 2003, 100, 10506-10511. [CrossRef] [PubMed]

37. Simoncini, T.; Mannella, P.; Fornari, L.; Caruso, A.; Willis, M.Y.; Garibaldi, S.; Baldacci, C.; Genazzani, A.R. Differential signal transduction of progesterone and medroxyprogesterone acetate in human endothelial cells. Endocrinology 2004, 145, 5745-5756. [CrossRef] [PubMed]

38. Bitran, D.; Shiek, M.; McLeod, M. Anxiolytic effect of progesterone is mediated by the neurosteroid allopregnanolone at brain GABAA receptors. J. Neuroendocrinol. 1995, 7, 171-177. [CrossRef] [PubMed] 
39. Gabbay, V.; Mao, X.; Klein, R.G.; Ely, B.A.; Babb, J.S.; Panzer, A.M.; Alonso, C.M.; Shungu, D.C. Anterior cingulate cortex \{gamma\}-aminobutyric acid in depressed adolescents: Relationship to anhedonia. Arch. Gen. Psychiatry 2012, 69, 139-149. [CrossRef] [PubMed]

40. Klaiber, E.L.; Broverman, D.M.; Vogel, W.; Peterson, L.G.; Snyder, M.B. Individual differences in changes in mood and platelet monoamine oxidase (MAO) activity during hormonal replacement therapy in menopausal women. Psychoneuroendocrinology 1996, 21, 575-592. [CrossRef]

41. Sherwin, B.B. Hormones, mood, and cognitive functioning in post-menopausal women. Obstet. Gynecol. 1996, 87, 20S-26S. [CrossRef]

42. Archer, J.S. NAMS/Solvay Resident Essay Award. Relationship between estrogen, serotonin, and depression. Menopause 1999, 6, 71-78. [CrossRef] [PubMed]

43. Kruijver, F.P.; Balesar, R.; Espila, A.M.; Unmehopa, U.A.; Swaab, D.F. Estrogen-receptor-beta distribution in the human hypothalamus: Similarities and differences with ER alpha distribution. J. Comp. Neurol. 2003, 466, 251-277. [CrossRef] [PubMed]

44. Backman, T.; Huhtala, S.; Blom, T.; Luoto, R.; Rauramo, I.; Koskenvuo, M. Length of use and symptoms associated with premature removal of the levonorgestrel intrauterine system: A nation-wide study of 17,360 users. Br. J. Obstet. Gynaecol. 2000, 107, 335-339. [CrossRef]

45. Pagano, H.P.; Zapata, L.B.; Berry-Bibee, E.N.; Nanda, K.; Curtis, K.M. Safety of hormonal contraception and intrauterine devices among women with depressive and bipolar disorders: A systematic review. Contraception 2016, 94, 641-649. [CrossRef] [PubMed]

46. Lopez, L.M.; Kaptein, A.A.; Helmerhorst, F.M. Oral contraceptives containing drospirenone for premenstrual syndrome. Cochrane Database Syst. Rev. 2012, CD006586. [CrossRef] [PubMed]

(C) 2018 by the authors. Licensee MDPI, Basel, Switzerland. This article is an open access article distributed under the terms and conditions of the Creative Commons Attribution (CC BY) license (http:/ / creativecommons.org/licenses/by/4.0/). 